\title{
Development of a model care pathway for the management of Hymenoptera venom allergy: evidence-based key interventions and indicators
}

\author{
Maria Beatrice Bilò ${ }^{1,2^{*}}$, Alice Corsi ${ }^{3}$, Valerio Pravettoni ${ }^{4}$, Donatella Bignardi ${ }^{5}$, Patrizia Bonadonna ${ }^{6}$, \\ Oliviero Quercia ${ }^{7}$, Marina Mauro ${ }^{8}$, Elio Novembre ${ }^{9}$, Rebecca Micheletti ${ }^{10}$ and Roberto Papa ${ }^{11}$
}

\begin{abstract}
Background: Hymenoptera venom allergy (HVA) is an underestimated condition representing an important cause of morbidity and mortality worldwide. Preventing future allergic reactions in patients who have already developed a systemic reaction is based on the correct management of the acute phase of the reaction followed by a correct diagnosis and, where indicated, prescription of adrenaline autoinjectors and VIT. A possible strategy to optimize care processes and to improve outcomes is the implementation of a Diagnostic and Therapeutic Care Pathways, also known as Integrated Care Pathways or Clinical Pathways (CPWs). The aim of the care pathway is to enhance the quality of care by improving risk-adjusted patient outcomes, promoting patient safety, increasing patient satisfaction, and optimizing the use of resources. To our knowledge, currently in Italy as well as in Europe, there is no CPWs codified for the management of HVA patients. This paper describes the development of the clinical content of a care pathway for the management of HVA.
\end{abstract}

Methods: The methodology applied is based on the eight step method to build the clinical content of an evidencebased care pathway suggested by Lodewijckx et al.

Results: Three hundred and seventeen different clinical activities were extracted from the selected literature. The expert panel was involved in their evaluation, expressing a judgment of relevance through the Delphi study. As a result, 126 clinical activities were appraised to be valid and feasible. The final recommendations (126) were translated into 123 key interventions. Six indicators were produced by the clinical activities.

Conclusion: A set of 123 key interventions and of six process indicators were found to be appropriate for the development and standardization of the clinical content of the Hymenoptera venom allergy care pathway.

Keywords: Care pathway, Clinical pathway, Core activity, Flow diagram, Hymenoptera venom allergy, Key interventions, Quality indicators

*Correspondence: m.b.bilo@univpm.it

${ }^{1}$ Allergy Unit, Department of Clinical and Molecular Sciences, Università Politecnica delle Marche, Ancona, Italy

Full list of author information is available at the end of the article

\section{Background}

Hymenoptera venom allergy (HVA) is an underestimated condition representing an important cause of morbidity and mortality worldwide. It can occur with varying degrees of severity (from local to anaphylactic reactions) and can sometimes be fatal. According to the data from the European Anaphylaxis Registry, HVA is the first 
cause of severe reactions in adults and the second in children (48.2\% and $20.2 \%$ respectively) [1]. In different countries, HVA is responsible for about $20 \%$ of the total cases of fatal anaphylaxis [2]. Overall, the incidence of mortality in the various European countries is between 0.03/million/year in Italy and 0.48 in France. However, mortality data are generally underestimated, as deaths are likely to be attributed by mistake to other causes, in particular to cardiac disorders. Moreover, up to $8 \%$ of adult patients with HVA may simultaneously suffer from a systemic mastocytosis (SM). SM is a clonal mast cell (MC) disease that can lead to potentially fatal anaphylactic reactions caused by excessive MC mediator release. Anaphylaxis is the most severe clinical manifestation of $\mathrm{SM}$ and is characterized by hypotension and syncope in the absence of urticarial and angioedema [3].

Hymenoptera venom allergy diagnosis is based on clinical history and results of in vivo and in vitro tests (mainly, specific IgE detection) [4]. Skin tests are the gold standard for diagnosis and should be carried out at least 2 weeks after the last sting, to exclude a false negative response during the refractory period. The presence of serum specific IgE to Hymenoptera venoms can be detected immediately after sting, even if the best period for their determination is $1-4$ weeks after the sting. Diagnosis could be complicated by sensitization to multiple venoms (Apis mellifera/vespids or Vespula spp./Polistes dominula) in patients who have not identified the stinging Hymenoptera. The availability on the market of some major allergens expressed in recombinant form allows evaluating the specific IgE to individual molecular markers (CRD, Component-Resolved-Diagnosis). CRD may discriminate between primary sensitization and crossreactivity in patients with double and multiple positivity of diagnostic tests with whole extracts [5].

As for therapy, adrenaline is the treatment of choice for acute anaphylaxis; it slows the progression of symptoms and can prevent the development of fatal or biphasic reactions [6]. All patients with a history of an anaphylactic reaction should be provided with an adrenaline autoinjector [7]. Venom immunotherapy (VIT) is the most effective treatment for subjects who developed a systemic allergic reaction (SR) after Hymenoptera sting, since currently it is the only treatment able to effectively prevent SR in case of a re-sting even after its discontinuation [8].

Preventing future allergic reactions in patients who have already developed a SR is based on the correct management of the acute phase of the reaction followed by a correct diagnosis and, where indicated, prescription of an adrenaline autoinjector and VIT.

A possible strategy to optimize care processes and to improve outcomes is the implementation of Diagnostic and Therapeutic Care Pathways, also known as
Integrated Care Pathways or Clinical Pathways (CPWs). CPWs are complex interventions for mutual decisionmaking, organization and standardization of predictable care for a well-defined group of patients during a welldefined period [9].

The aim of the care pathway is to enhance the quality of care by improving risk-adjusted patient outcomes, promoting patient safety, increasing patient satisfaction, and optimizing the use of resources [9]. Clinical pathways are primarily considered to be tools for designing care processes, implementing clinical governance, streamlining delivered care, improving the quality of clinical care and ensuring that clinical care is based on the latest research.

Standardization of the clinical care process through integration of evidence-based knowledge has proven to be an effective strategy for reducing unwanted variations in treatment, minimizing the probability of medical errors and improve the quality of the healthcare $[10,11]$. The reduction of variability is in fact the key to quality.

Evidence-based clinical pathways can be effective tools for organizing evidence into multidisciplinary care plans for local work processes and can be a model for making evidence more actionable for providers at the point of care [12]. To our knowledge, currently in Italy as well as in Europe, there is no CPWs codified for the management of HVA patients.

This paper describes the development of the clinical content of a care pathway for the management of HVA.

\section{Methods}

The methodology applied is based on the eight-step method to build the clinical content of an evidence-based care pathway as suggested by Lodewijckx et al. [10]. The steps applied for the development of the model pathway are shown below.

\section{Selection of an expert panel}

A national expert panel was involved in each step of the development of the model pathway, in order to guarantee the clinical validity and practicability of the path.

The expert panel consisted of seven doctors with clinical and scientific expertise in HVA, two doctors with clinical and scientific expertise in emergency medicine and two pharmacists.

Moreover, the expert panel was supported by a technical-methodological coordination group made of one medical doctor, with scientific expertise in development and implementation of care pathways, one medical allergist from the expert panel and two post-graduate medical doctors (one post-graduate medical doctor in Allergy and Clinical Immunology and another one in Hygiene and Preventive Medicine and Public Health). 
A first face-to-face meeting of the panel members was conducted in July 2018 to choose the protocol for search, evaluation and synthesis of best evidence for the realization of the CPW.

\section{Literature search and selection of recommendations}

To identify the reference guidelines (LGs) an extensive literature review was conducted from July 2018 up to September 2018, with the aim of identifying the good practices to be included in the document.

The following resources were explored: (i) websites of European Academy of Allergy and Clinical Immunology (https://www.eaaci.org/); (ii) websites of The American Academy of Allergy, Asthma and Immunology (https:// www.aaaai.org/); (iii) National Institute for Health and Clinical Excellence (NICE) (www.nice.org.uk); (iv) electronic database (Medline).

For Medline, the following terms were used: "guidelines" combined with "anaphylaxis", "adrenaline" "Hymenoptera venom allergy", "venom immunotherapy", and "Systemic mastocytosis" combined with "Hymenoptera venom allergy", "Allergy", "Anaphylaxis". All synonyms for these terms were included in the search.

Participants were given the opportunity to provide any additional recommendations from other good quality supplementary documents (Position Paper and Review) or, alternatively, to produce specific recommendations indicated as Good Practice Point (GPP), in the absence of evidence of effectiveness in the selected LGs.

The selected literature was thoroughly screened for identification of all possible recommendations by the members of the technical-methodological coordination group. The recommendations were extracted and listed both in English and Italian languages, and the corresponding literature sources were recorded.

\section{Delphi consensus method}

The Delphi method was used in order to select relevant statements [13].

Two rounds were used to reach consensus. The first Delphi survey was conducted through email between October 2018-November 2018. In the first round, the panelists rated the relevance of each recommendations on a scale of 1 to 9 , with 1 being certainly irrelevant and 9 being certainly relevant. They have also had the chance to record comments to explain their scores.

Completed score-sheets with any comments were then returned by email to the technical-methodological coordination group. The scores and comments were recorded onto a central database file. Feedback on the round one responses was provided to all panelists through central tendencies (median, mode) of each statement.
All panel members attended the second round faceto-face meeting, which occurred in December 2018, to discuss the results of the first round. The same analysis procedure was applied to the second round rating during the meeting. Consensus was defined as agreement by at least $75 \%$ of the panel members. All the statements that were rated 8 or 9 by at least $75 \%$ of the panelists in round two have been included in the final clinical pathway.

\section{Selection of key interventions}

One of the active ingredients in care pathways is the integration of a set of evidence-based key interventions (KI) that may assist clinicians in selecting the best treatment options and in delivering safe and effective care.

Therefore, the selected recommendations were translated into key interventions. Each key intervention has been included a detailed description (rationale), which addresses the reason why the key intervention is performed (illustrating the expected impact on patient outcomes) and a description of the intervention (core activity), as a set of good quality tests, which define the exact content of the key intervention to be guaranteed to the patient.

The core activities allow contextualization of specific operating activities in greater details and meet a series of criteria: (i) core activities almost always require to be carried out by a specific member of the clinical care team (doctor, nurse, pharmacist etc.); (ii) core activities need to be carried out at a specific point in the treatment pathway or at a specific stage.

\section{Translation into a set of clinical indicators}

To study the quality of care and the impact of care pathways appropriately, a valid and feasible set of process and outcome indicators needs to be defined. Therefore, besides the set of key interventions, it was necessary to develop a set of process and outcome indicators to verify compliance to key interventions and to follow up the impact on outcomes.

Clinical indicators are measures of clinical care which may, when assessed over time, provide a method of assessing the quality and safety of care. They are measures of the process or outcomes of patient care and they are used by health systems and services to identify areas of concern which might require further review or development. They are potentially important tool designed to help clinicians and healthcare organizations to assess the quality of care being provided against agreed evidence bases recommendations [14].

The key interventions that had obtained an average score higher than 8.8 were translated into a set of clinical indicators, which are relevant to study quality of care and impact of care pathways in HVA patients. The reason for 
choosing this assessment threshold is that identifying one or more indicators for each of the selected recommendations would have led to the production of a large number of indicators and standards difficult to measure. The group was given the opportunity to integrate the list with further adequately motivated performance indicators.

According to the commonly used Donabedian Model, quality of healthcare can be measured by three types of indicators: structure, process and outcome indicators [14]. In the HVA CPW only process indicators have been identified. The process indicator measures the appropriateness and completeness of information obtained through clinical history, physical examination, diagnostic tests; justification of diagnosis and therapy; technical competence in the performance of diagnostic and therapeutic procedures, evidence of preventive management in health and illness; coordination and continuity of care and therapy [15].

\section{Flow-diagram development}

Finally, a process flow diagram was developed. CPWs can be viewed as algorithms as much as they offer a flow chart format of the decisions to be made and the care to be provided for a given patient or patient group for a given condition in a step-wise sequence; these detail the recommended algorithm of actions and level of care. The hierarchical algorithm is a snapshot of the process at its highest level; it focuses the user's attention on the main decision nodes. It provides a mental model for the multidisciplinary team and helps to manage complexity [15].

\section{Results}

Seventeen publications, among which six were international guidelines, were identified from literature search, which were screened for identification of all possible statements/recommendations [3, 6-8, 16-28].

There was no need to review any evidence with a GPP judgment from the panel of experts.

Three hundred and seventeen different recommendations were extracted from the selected literature. The expert panel was involved in their evaluation, expressing a judgment of relevance through the Delphi method. One hundred twelve recommendations had score (median, mode) higher than eight, one hundred ten recommendations had reached the agreement of at least $75 \%$ of the panel and were including in the CPW. Out of the remaining 205 recommendations, 202 had score between 4 and 7.9 and three had score lower than 4 . The participants received a report, which illustrated the results of the first evaluation for each recommendation. A subsequent consensus meeting was held with the entire expert panel in order to discuss in the areas of disagreement and other two recommendations (out of 112) with score (median, mode) higher than eight that had not reached the agreement at $75 \%$ and recommendations with 4-7.9 score to make a final selection. The discussion then focused on the areas of disagreement that emerged. Consensus was reached for 16 of 204 recommendations.

As a result, 126 recommendations were appraised to be valid and feasible. They were categorized into five groups: 10 statements on emergency treatment of patients with HVA (ET), 27 statements on diagnosis of HVA (D), 26 statements on pharmacological therapy (PT), 47 statements on immunotherapy (VIT) and finally 16 on mastocytosis and HVA $(\mathrm{M})$.

The final recommendations (126) were then translated into 123 key interventions (similar recommendations have been combined into a single key intervention). An example of a key intervention (rational and core activity) is provided in Fig. 1. All key interventions are listed in Table 1.

The key interventions were presented by means of a process flow diagram (Fig. 2). All the flow chart forms were numbered in order to link them to the recommendations and related key interventions.

Six process indicators were produced by the recommendations that had obtained an average score higher than 8.8 (Table 2).

Figure 3 summarizes the development of the clinical pathway and its results.

Finally, the document was submitted to a panel of other 17 specialists responsible for Allergy Departments in Italy, who did not produce any additional remarks, in particular about $\mathrm{KI}$ and indicators. The core activities will then be included within Operative pathways, which are the real representation of routes at the local level, based on resources and available skills. The final document was then shared with the Italian Federation of patient associations (FederAsma e Allergie onlus). Specific questions from patient's point of view asked by the Italian Federation found their answer in different parts of the document (KI and flow-chart).

\section{Discussion}

Hymenoptera venom allergy is an important cause of morbidity worldwide and may occur with varying degrees of severity and can sometimes be fatal.

The management of the patients who have developed a SR after a Hymenoptera sting provides for a correct management in the emergency treatment, followed by a correct diagnosis that forms the basis for the treatment, represented by the prescription of an adrenaline autoinjector, and VIT, where necessary.

CPWs are used to improve quality of care, standardize care and maximize the outcomes for specific groups of patients [11]. A CPW with the goal to increase the 
Clinical Activity PT2 Adrenaline slows the progression of symptoms and can prevent the development of fatal or biphasic reactions. (I2, I19)

\section{Key intervention}

- Rational Adrenaline, $\alpha$ - and $\beta$-agonist, is able to oppose both the release and the effect of chemical mediators during anaphylaxis and the development of fatal or biphasic reactions

- Core Activity Administer adrenaline as a first-choice anaphylaxis treatment, including for the prevention of biphasic reactions

Clinical Activity VIT12 VIT is indicated in the following circumstances: a) adults and children with a systemic reaction involving other apparatus besides the skin. b) systemic skin reaction at high risk of exposition and/or impairment of quality of life in adults. c) patients with clonal mast cell disorder and a history of a systemic reaction, even though sensitization can be weak or sometimes transitory. (I20)

\section{Key intervention}

- Rational Specific immunotherapy for hymenoptera venom is the therapy of choice for subjects who developed a systemic reaction after hymenoptera sting or developed a systemic skin reaction at high risk of exposition and/or impairment of quality of life or finally in patient with clonal mast cell disease, since it can induce a tolerance to venom and it able to protect patients from systemic reaction after subsequent stings

- Core Activity Indicate VIT to a) adults and children with a systemic reaction involving other apparatus besides the skin. b) systemic skin reaction at high risk of exposition and/or impairment of quality of life. c) patients with clonal mast cell disorder and a history of a systemic reaction, even though sensitization can be weak or sometimes transitory

Fig. 1 Examples of a key intervention. PT pharmacological therapy, VIT venom immunotherapy

level of medical awareness on HVA and outline clear care paths for these patients is lacking. Therefore, this document aims to identify a shared, multidisciplinary path, based on the most recent national and international scientific evidence (quality guidelines were used for the most part) and supported by the consensus of different specialists with extensive experience in emergency treatment (2) and clinical expertise and scientific knowledge of HVA (7). The multidisciplinary expert group was fundamental for the development of the CPW, making it possible to deal comprehensively with the management of the HVA patients.

The main objective is to standardize the behavior of professionals with regard to taking care, diagnosis, treatment and follow-up of allergic patients with systemic reactions due to Hymenoptera stings, so as to ensure the maximum degree of appropriateness of the interventions and health services and minimizing the degree of variability in clinical decisions.
Professional uncertainty and the scarce use of medical evidence seem to be the key elements in many problems dealing with health care variations, due to their possible links with medical errors. Reducing variations by standardizing clinical processes is an effective tool to minimize the probability of medical errors [29].

Given that HVA is the most frequent cause of severe allergic reactions, and still an epidemiologically underestimated condition, this codified approach also allows a better assessment of the impact of the disease and its epidemiological weight.

Moreover, we developed a set of indicators, which are potentially important tools able to help clinicians and healthcare organizations to assess the quality of care being provided by agreed evidence-based recommendations. Therefore, the selected indicators are relevant for research on quality of management of HVA patients. These indicators should be embedded in daily clinical practice to encourage continuous quality assessment 


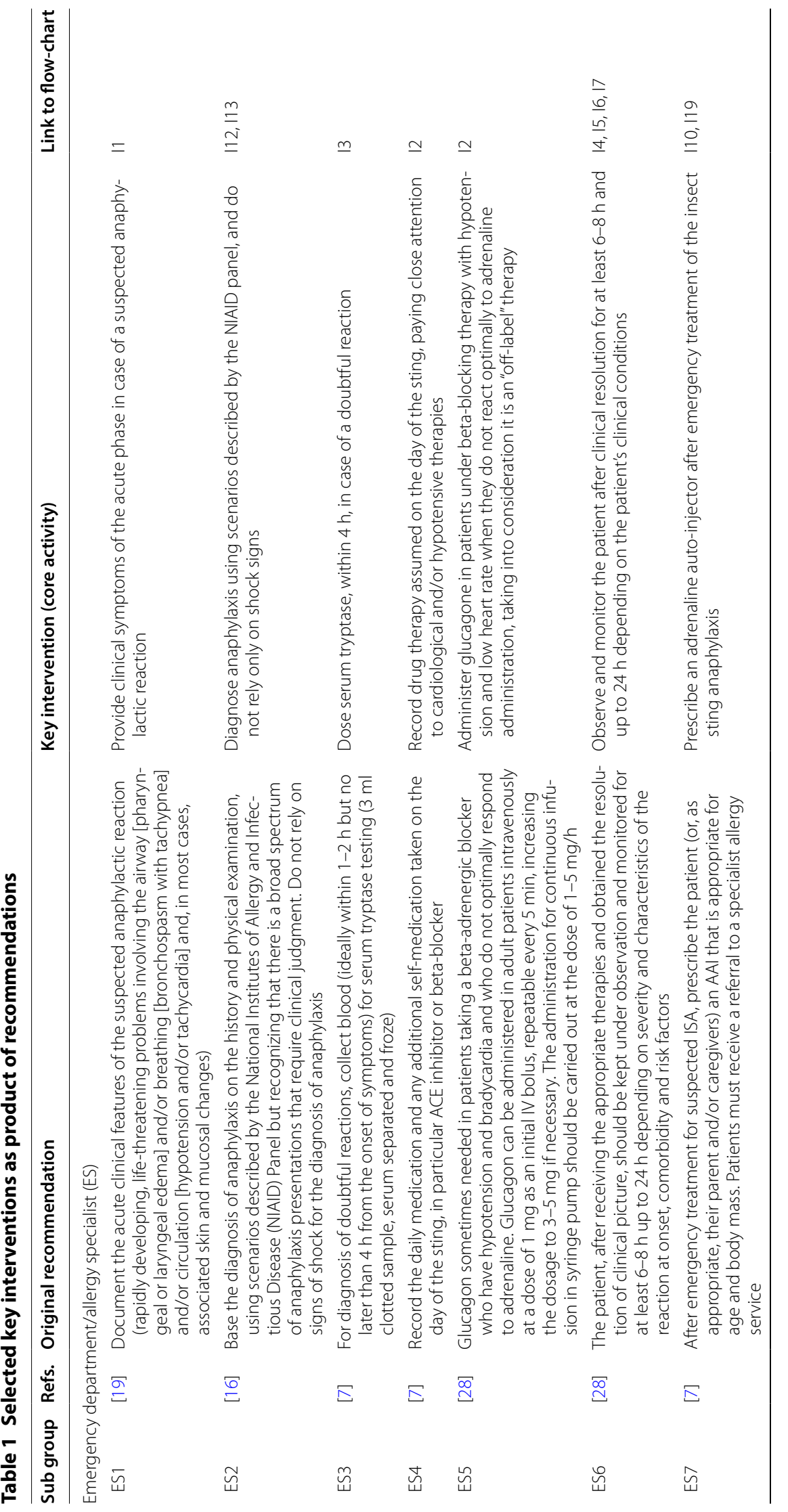




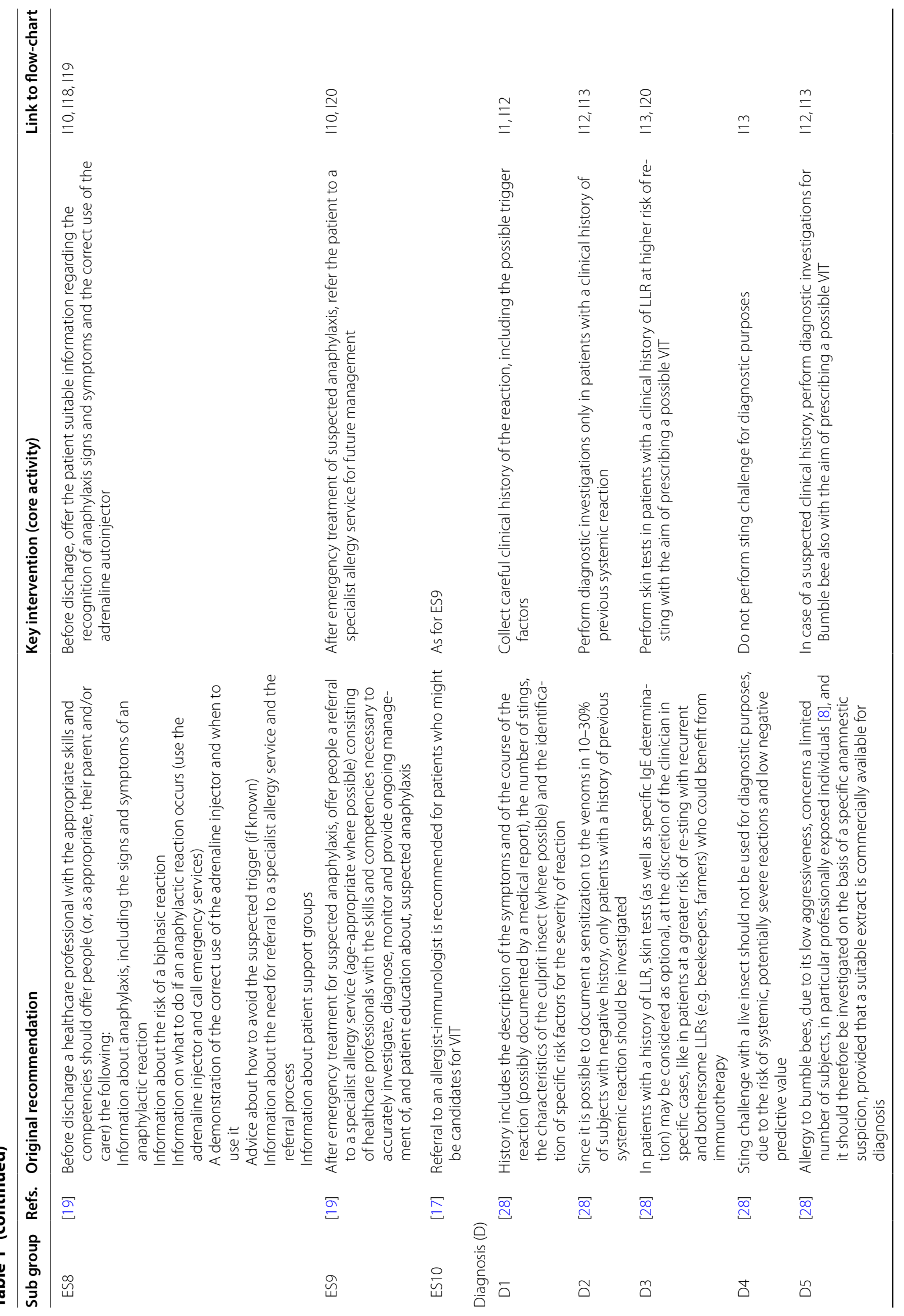




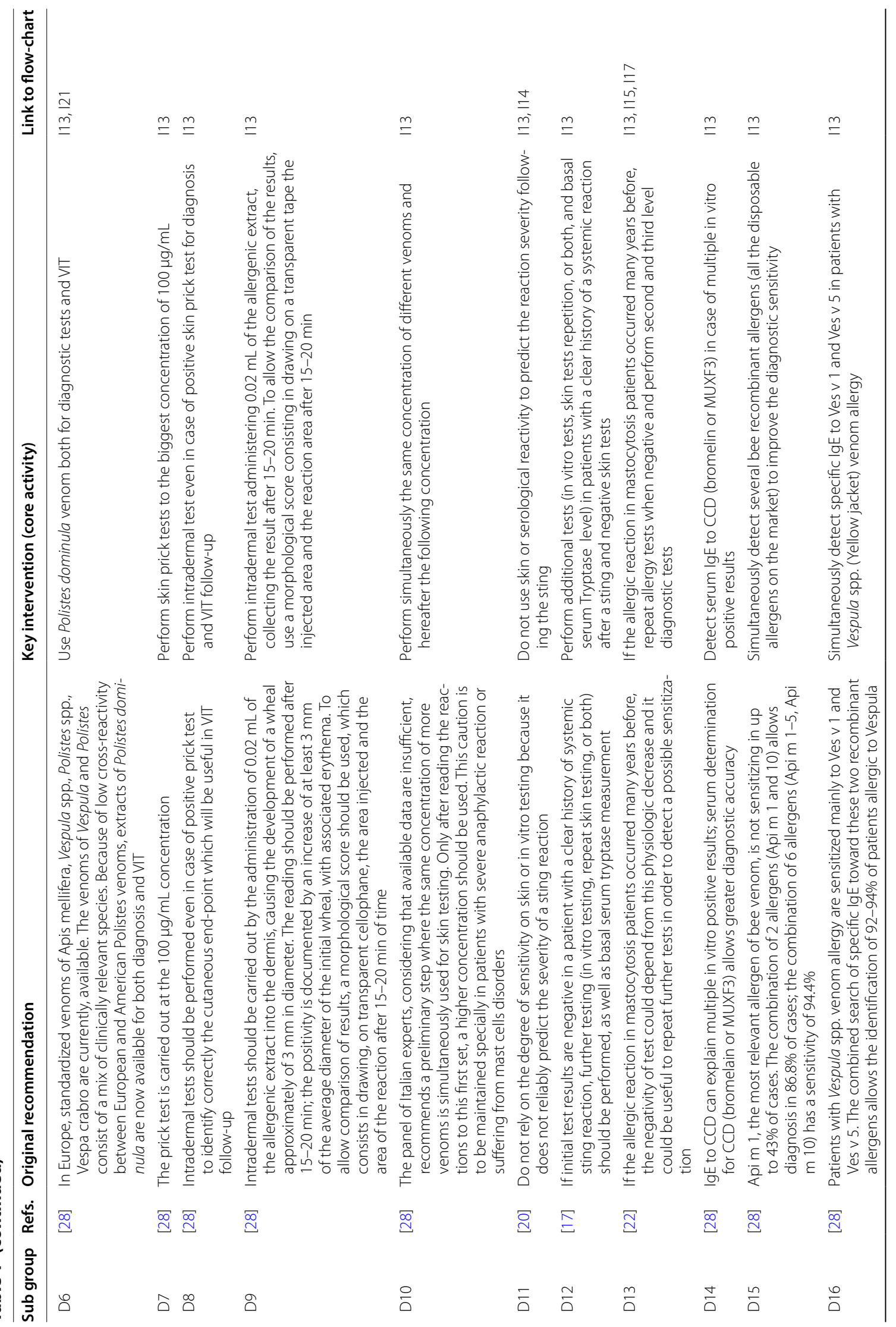




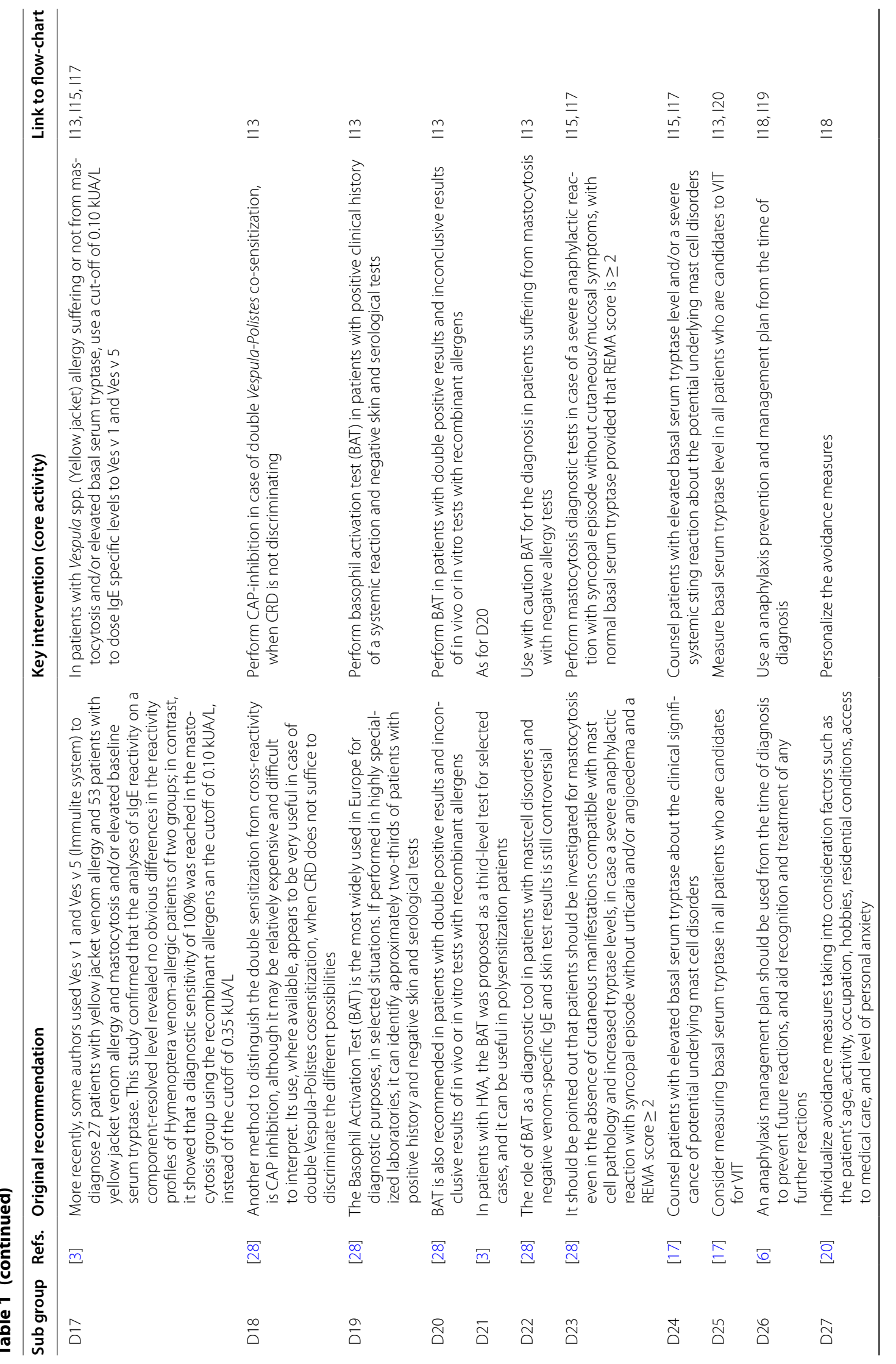




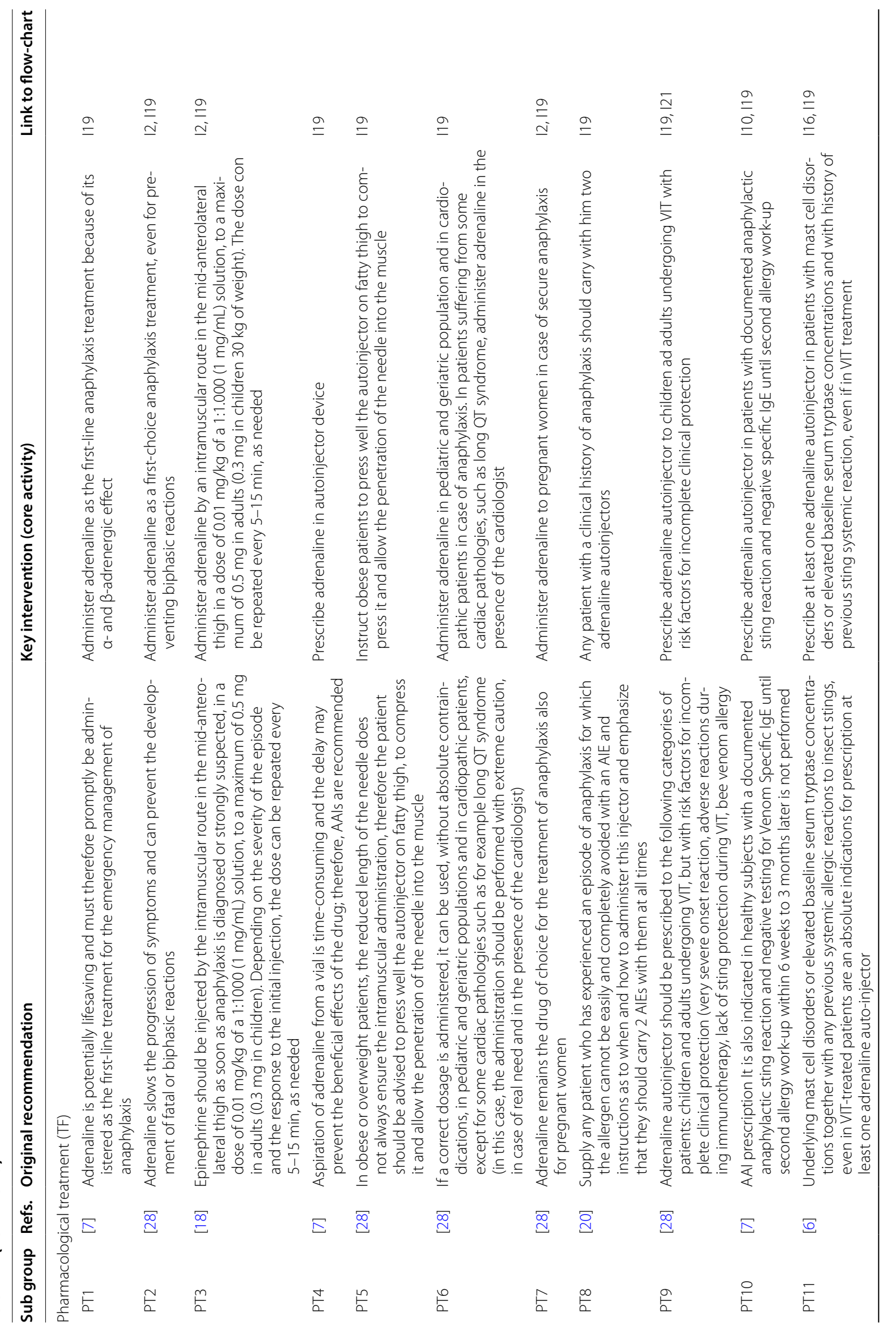




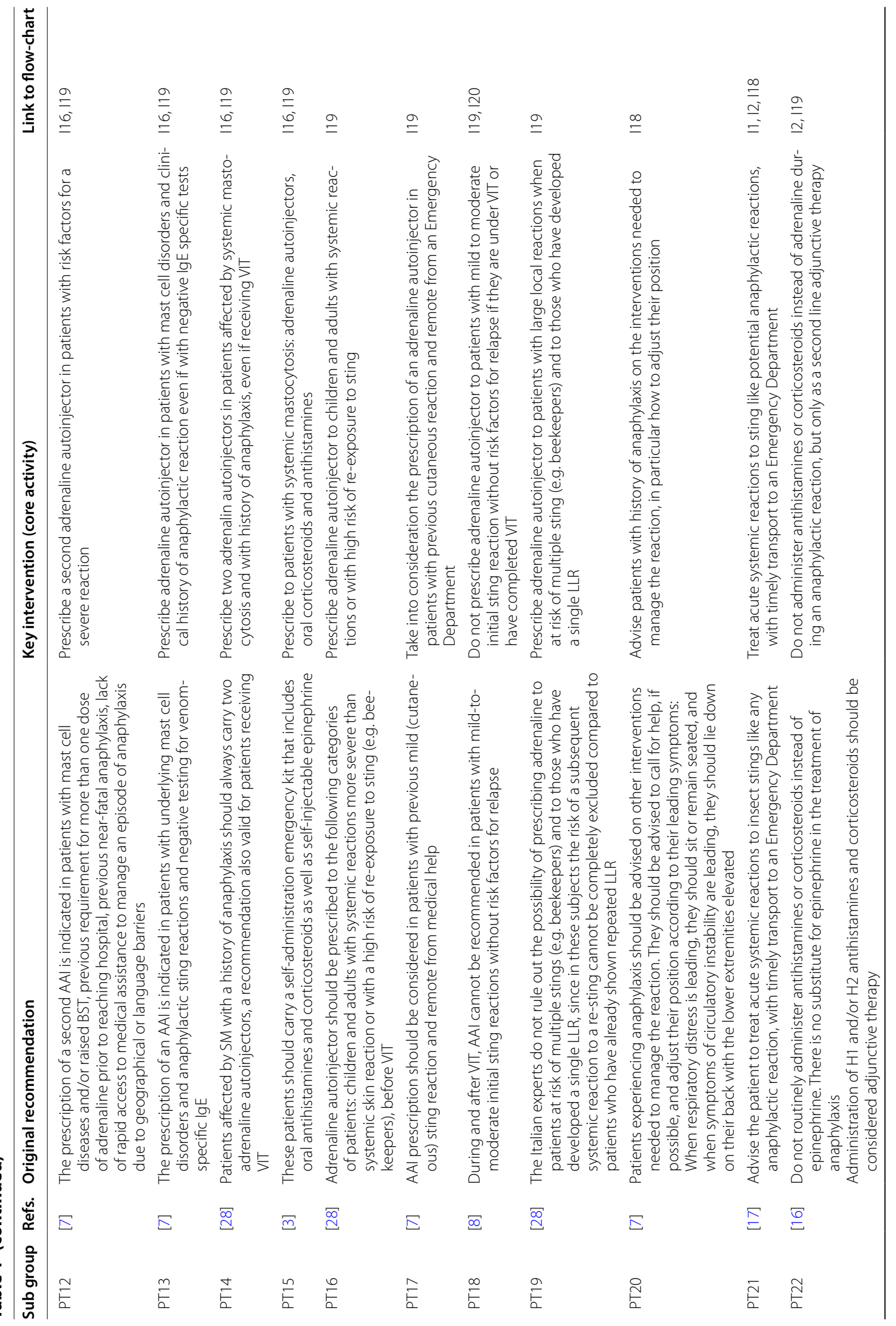




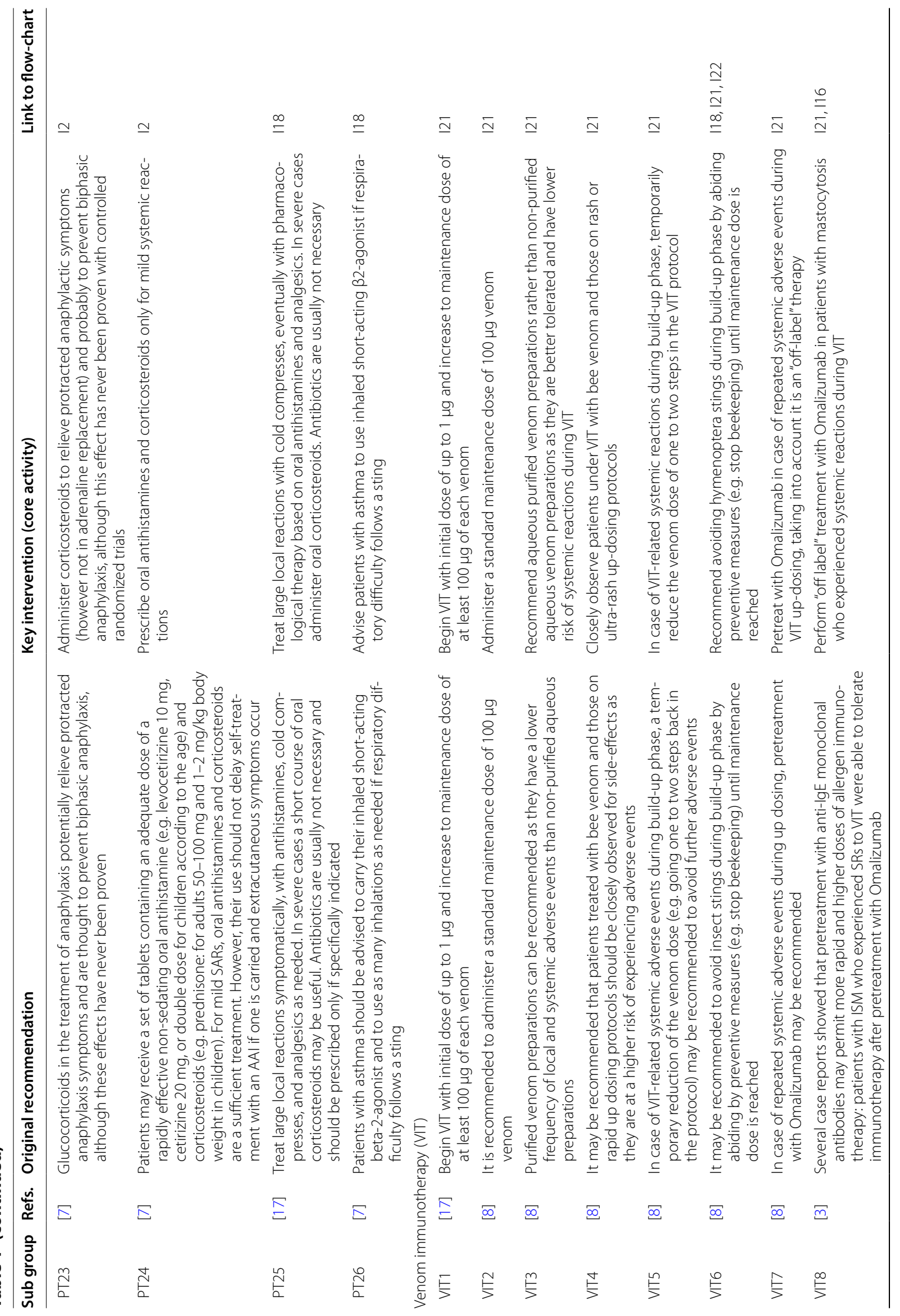




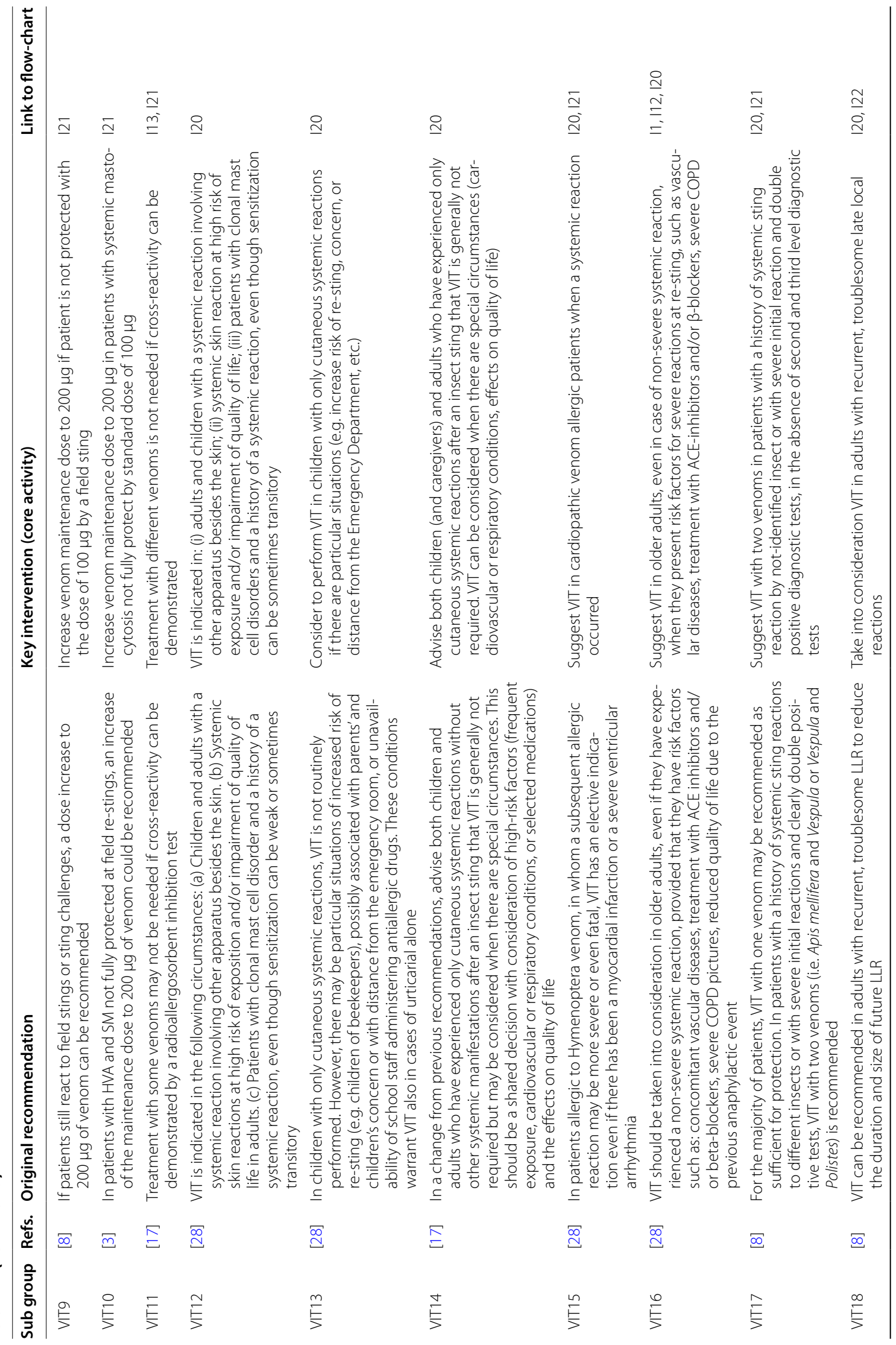




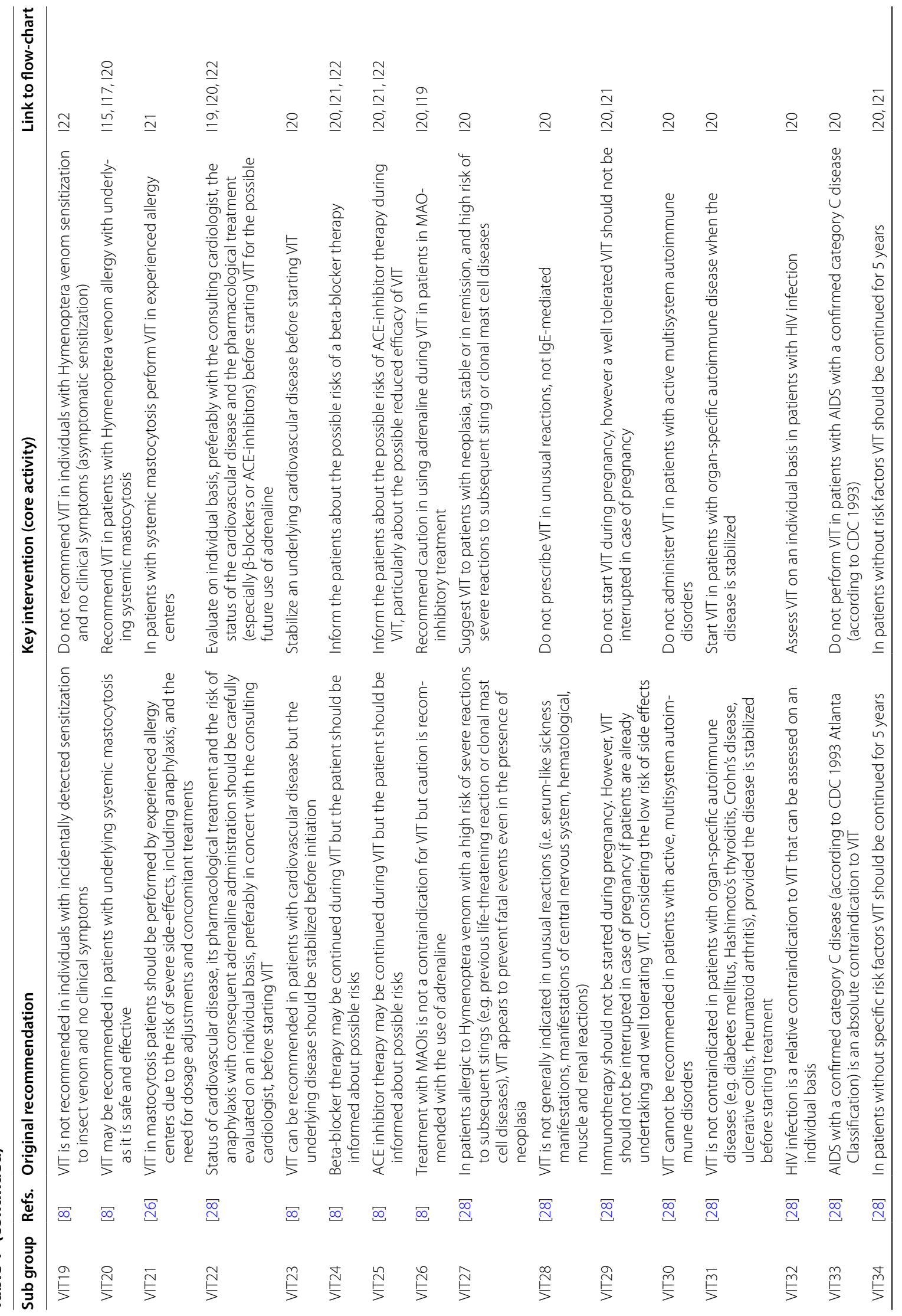




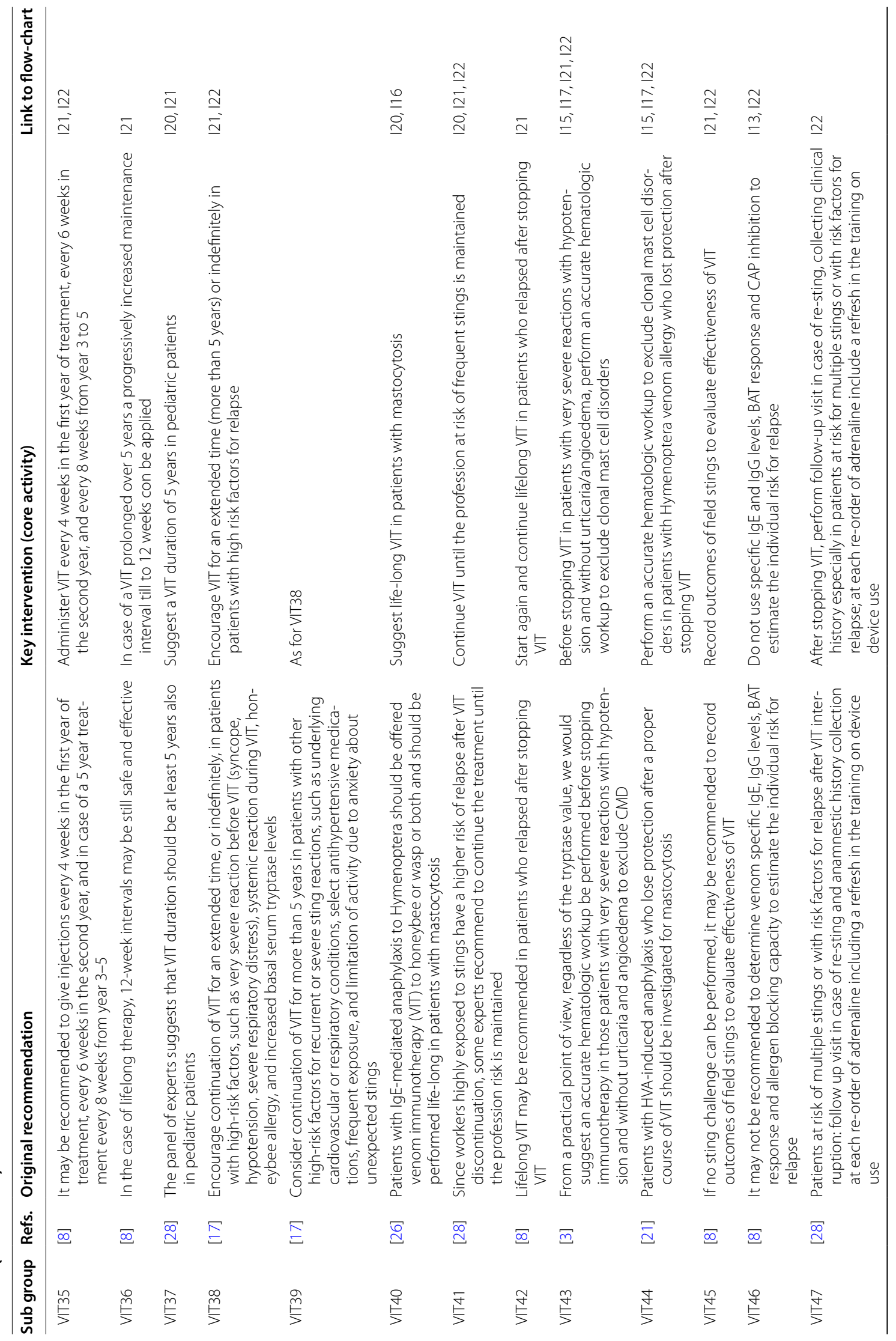




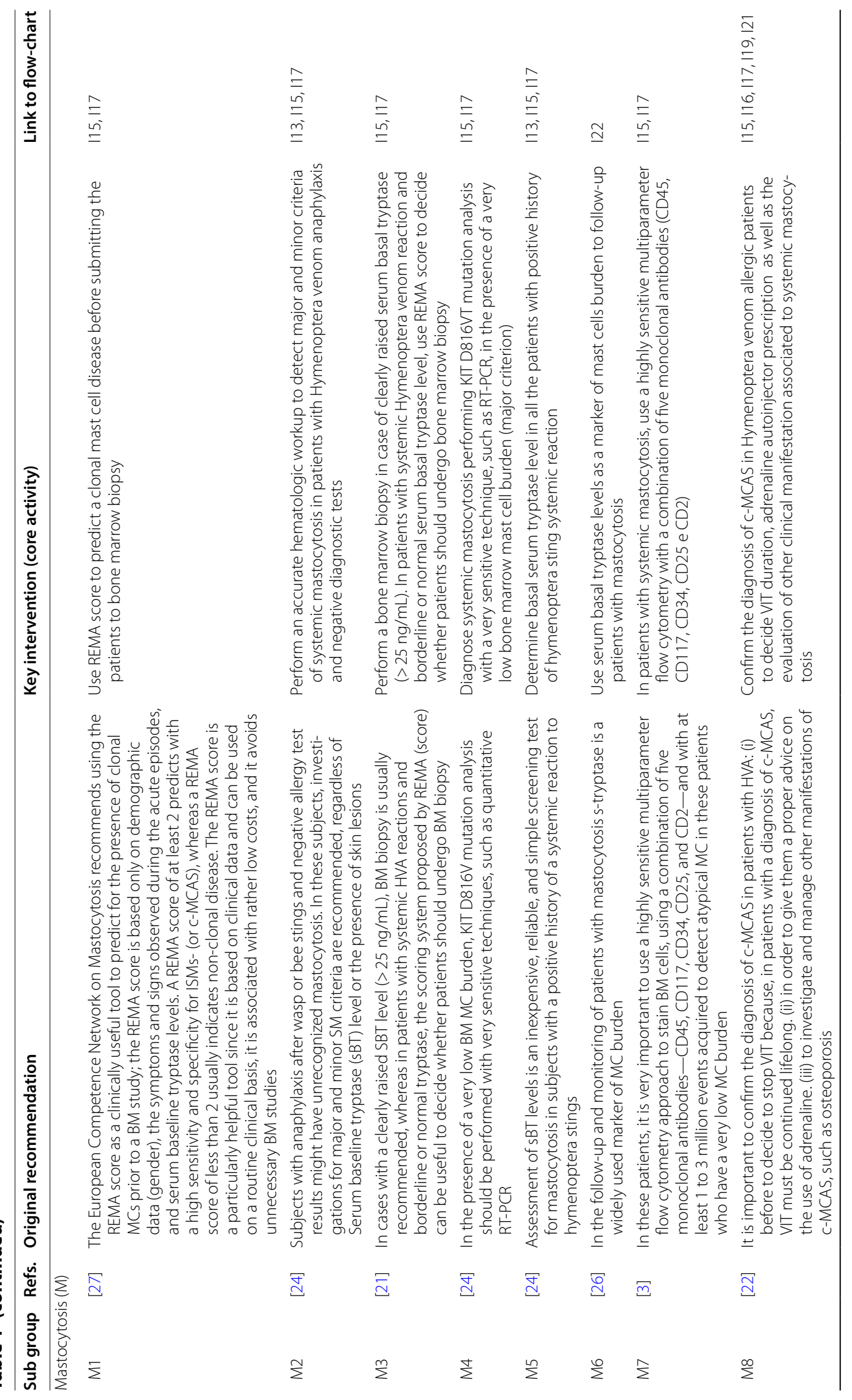




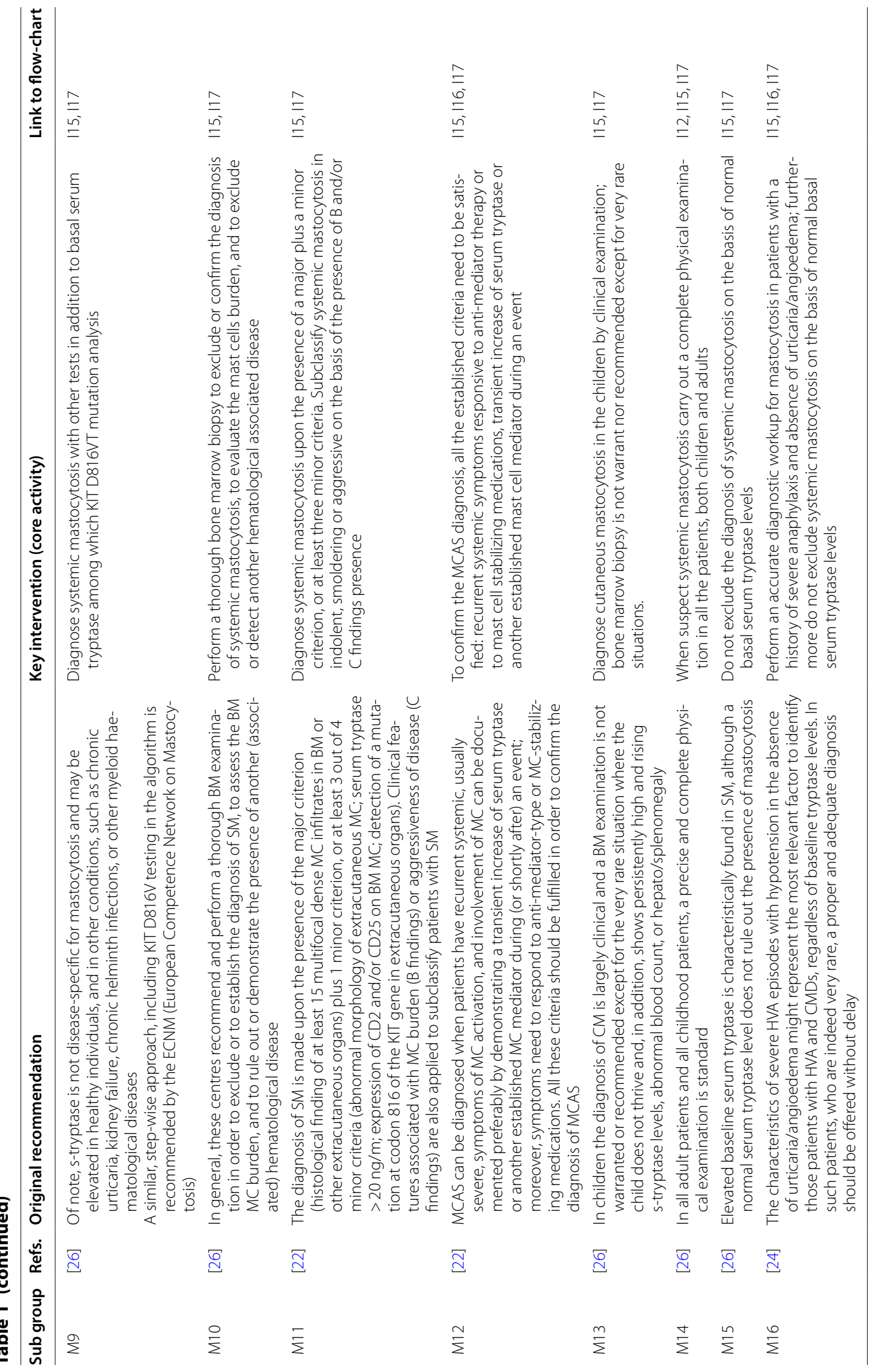




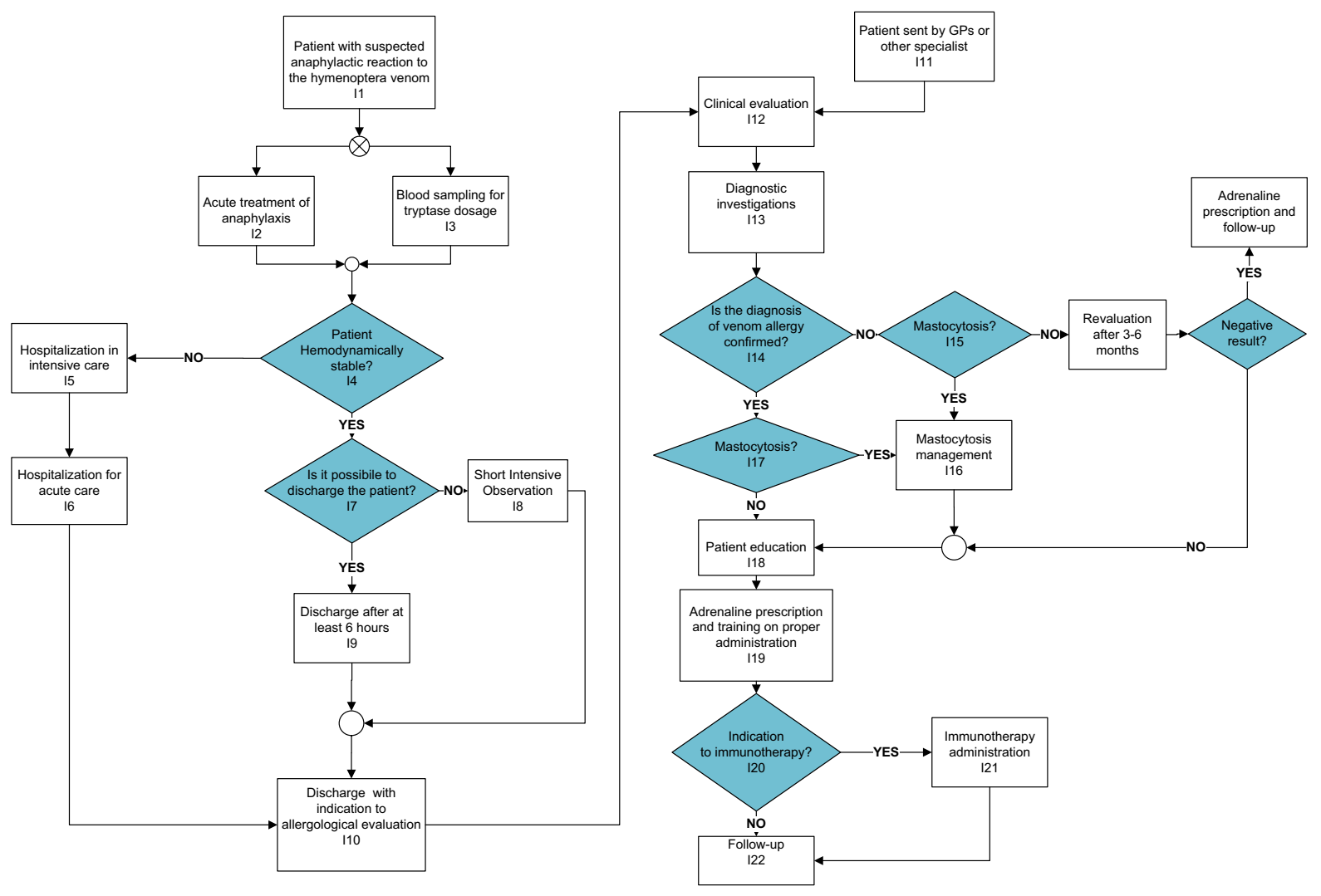

Fig. 2 Process flow diagram for the management of HVA patients

Table 2 Process and outcomes indicators for the management of HVA patients

\begin{tabular}{|c|c|c|c|c|}
\hline Number & Indicator & Type & Unit & Value (\%) \\
\hline 1 & $\%$ of patients with severe anaphylaxis receiving acute adrenaline treatment in emergency room (ER) & Process & Percent & 90 \\
\hline 2 & $\%$ of patients discharged from ER. with allergological evaluation indication & Process & Percent & 90 \\
\hline 3 & $\begin{array}{l}\text { \% of patients prescribed a second adrenaline auto-injector if clinically indicated (patients with mast cell } \\
\text { diseases and/or with increased baseline serum tryptase levels, previous need for more than one dose of } \\
\text { adrenaline before reaching the hospital, almost fatal previous anaphylaxis, lack of rapid access to anaphy- } \\
\text { laxis medical assistance due to geographical or linguistic barriers, patient's habitus) }\end{array}$ & Process & Percent & 90 \\
\hline 4 & $\%$ of patients with multiple positivity in whom complete CRD was performed & Process & Percent & 95 \\
\hline 5 & $\begin{array}{l}\% \text { of patients with severe anaphylactic reaction with syncopal episode without urticaria and/or angioedema } \\
\text { and a REMA score } \geq 2 \text { initiated for mastocytosis diagnostic investigations }\end{array}$ & Process & Percent & 80 \\
\hline 6 & $\begin{array}{l}\% \text { of patients with Hymenoptera venom allergy, myocardial infarction or severe ventricular arrhythmia } \\
\text { undergoing VIT }\end{array}$ & Process & Percent & 90 \\
\hline
\end{tabular}

$E T$ emergency treatment, D diagnosis, PT pharmacological therapy, VIT venom immunotherapy, $M$ mastocytosis

and improvement of care for Hymenoptera venom allergy patients. Six process indicators were selected. Process indicators measure the clinicians compliance to the key interventions in the care process. Key interventions are those that, based on evidence-based medicine, need to be performed to guarantee high-quality care, and that thus will have significant impact on patient outcomes.

It is of note that the document represents the first European HVA CPW produced according to a rigorous methodology. The CPW was made by an allergy expert panel and was submitted to other 17 experts, who 


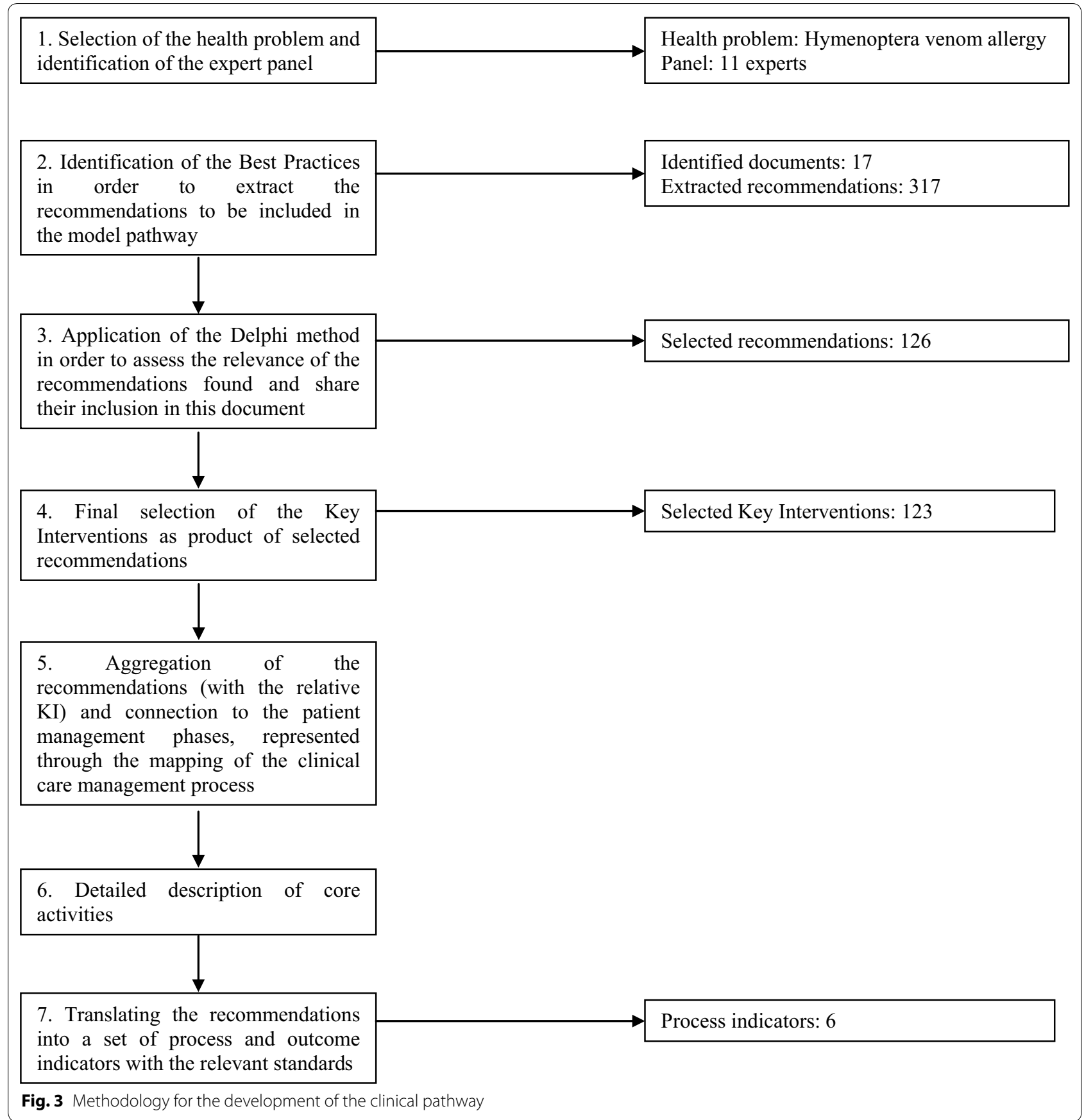

approved all the steps, including the KI, the process flow diagram, and the indicators, judged valid and applicable in clinical practice.

It is noteworthy that CPW benefited from the endorsement of three scientific societies (Italian Association of Hospital and Territorial Allergists and Immunologists, AAIITO-Italian Society of Allergology and Clinical Immunology, SIAAIC-Italian Society of Pediatric Allergy and Immunology, SIAIP) which plays an important role in clinical content development for care pathway, especially in terms of clinical support, expert networking and input of resources.

One limitation of the CPW process is the lack of patient involvement since the beginning of the document development. Patients can bring a different perspective to the quality improvement process, as they are likely to prioritize different aspect of care compared to clinicians. However, the definitive document was submitted to the 
Italian Federation of patient associations, which evaluated and shared the CPW.

Furthermore, we did not verify the indicators in specific clinical audits, which allows to obtain further information on the feasibility of data collection, on verification of adherence to the CPW and on any changes to effectively implement the path; however, this phase was not included in the project.

The next step of project is to translate and check the feasibility of the CPW at local Italian levels. This phase is particularly important as designing the care pathway content is a time-consuming process that requires resources and skills.

\section{Conclusion}

Developing the clinical care pathway may facilitate adequate integration of evidence-based knowledge into daily practice. For the first time in the field of HVA, by using the Delphi survey with 11 experts 123 key interventions were found to be appropriate for the development and standardization of the clinical content of the HVA care pathway. Next to the model pathway, six indicators were identified for monitoring and following up of Hymenoptera venom allergy patients.

Compliance to care pathways can be difficult, but has to be strived for, to deliver the best possible care for patients.

\begin{abstract}
Abbreviations
CRD: Component-Resolved-Diagnosis; VIT: Venom immunotherapy; HVA: Hymenoptera venom allergy; CPWs: Clinical pathways; GPP: Good Practice Point; Kl: Key interventions; ET: Emergency treatment; D: Diagnosis of HVA; PT: Pharmacological therapy; M: Mastocytosis and Hymenoptera venom allergy; LGs: Guidelines; SM: Systemic mastocytosis; SR: Systemic allergic reaction; MC:
\end{abstract} Mast cell.

\section{Acknowledgements}

We would like to acknowledge the logistic support of Andrea Comaschi and Ilaria Ugolini (Aristea Group) in the development of the project.

We thank Alk-Abellò Italy for the unconditional support to the project.

The authors are grateful to Dr. Sabrina Beltramini (pharmacist), Dr. Andrea Fabbri (emergency doctor), Dr. Rosaria Gerarda Polo (pharmacist), Dr. Annalisa Mattioli (emergency doctor), and Mrs Sandra Frateiacci (FederAsma e Allergie onlus) for their active collaboration.

The authors also thank the AVE (Allergy Venom Experts) group for the collaboration on the project. AVE is a group of Italian experts in the field of Allergy and Clinical Immunology who are also active members of the Italian Allergy and Clinical Immunology Societies (AAIITO, SIAIP, SIAAIC):

Alessandro Buonomo (UOC Allergologia, IRCCS Fondazione Policlinico Universitario Agostino Gemelli, Università Cattolica del Sacro Cuore, Roma); Gabriele Cortellini (Allergologia, UO Medicina Interna e Reumatologia, Rimini, Azienda Sanitaria della Romagna); Maria Teresa Costantino (Struttura Dipartimentale Centro Day Hospital, Allergologia ed Immunologia Clinica, Azienda Socio Sanitaria Territoriale di Mantova, Allergologia Interaziendale ATS Val Padana); Fabio Lodi Rizzini (SSVD Allergologia Spedali Civili di Brescia, Dipartimento Scienze Cliniche e Sperimentali, Università di Brescia); Donatella Macchia (SOS Allergologia e Immunologia Clinica, USL Toscana Centro, Ospedale San Giovanni di Dio, Firenze); Luigi Macchia (Scuola e cattedra di Allergologia ed Immunologia Clinica, Università di Bari); Carmen Montera (U.O. di Allergologia e Immunologia Clinica, Ospedale G. Fucito, Azienda Ospedaliero
- Universitaria San Giovanni di Dio e Ruggi d'Aragona, Salerno); Francesco Murzilli (UOSD di Allergologia Ospedale S.S. Filippo e Nicola, Avezzano (AQ)); Elide Anna Pastorello (Struttura Complessa Allergologia e Immunologia c/o ASST Grande Ospedale Metropolitano Niguarda - Scuola di Specializzazione in Allergologia e Immunologia Clinica c/o Università degli Studi di Milano); Vincenzo Patella (Centro Aziendale Provinciale per la Cura delle Malattie Allergologiche e immunologiche Gravi ASL Salerno, Ospedale Civile di Battipaglia (SA)); Silvia Peveri (UOSD Allergologia, Ospedale G. da Saliceto, AUSL di Piacenza); Federico Reccardini (SOC Pneumologia, Fisiopatologia Respiratoria, Azienda Sanitaria Universitaria Integrata di Udine); Luisa Ricciardi (Unità di Allergologia ed Immunologia Clinica, Ospedale Universitario AOU Policlinico G. Martino, Dipartimento di Medicina Clinica e Sperimentale, Università di Messina); Erminia Ridolo (Dipartimento di Medicina e Chirurgia, Università degli Studi di Parma); Antonino Romano Unità di Allergologia, Presidio Columbus, Roma - IRCCS Oasi Maria S.S., Troina); Livio Simioni (UOSD Allergologia, ULSS 2 Feltre (BL)); Danilo Villalta (SSD di Allergologia e Immunologia Clinica, Ospedale S. Maria degli Angeli, Pordenone).

\section{Authors' contributions}

MBB, AC, RP, RM wrote the paper. All authors participated in revision of the study manuscript. All authors read and approved the final manuscript.

\section{Funding \\ None.}

Availability of data and materials

Not applicable.

Ethics approval and consent to participate

Not applicable.

\section{Consent for publication}

Not applicable.

\section{Competing interests}

The authors declare that they have no competing interests.

\section{Author details}

${ }_{1}^{1}$ Allergy Unit, Department of Clinical and Molecular Sciences, Università Politecnica delle Marche, Ancona, Italy. ${ }^{2}$ Department of Internal Medicine, University Hospital Ospedali Riuniti di Ancona, Ancona, Italy. ${ }^{3}$ Postgraduate School of Allergy and Clinical Immunology, Università Politecnica delle Marche, Ancona, Italy. ${ }^{4}$ U.O.C. General Medicine-Immunology and Allergology, Foundation IRCCS Ca'Granda Ospedale Maggiore Policlinico, Milan, Italy.

${ }^{5}$ U.O.C. Allergology, Ospedale Policlinico San Martino, Genoa, Italy. ${ }^{6}$ U.S.D. Allergology Integrated University-Hospital of Verona, Verona, Italy. ${ }^{7}$ High Specialization Unit of Allergology, Hospital of Faenza, AUSL (Local Health Unit) of Romagna, Romagna, Italy. ${ }^{8}$ U.O.S. Allergology ASST Lariana, Como, Italy.

${ }^{9}$ Complex Organizational Unit of Allergology, University-Hospital A. Meyer, Florence, Italy. ${ }^{10}$ Postgraduate School of Hygiene and Preventive Medicine and Public Health, Università Politecnica delle Marche, Ancona, Italy. ${ }^{11}$ S.O. Hospital Medical Management, University Hospital Ospedali Riuniti di Ancona, Ancona, Italy.

Received: 4 November 2019 Accepted: 24 February 2020

Published online: 04 March 2020

References

1. Worm M, Moneret-Vautrin A, Scherer K, Lang R, Fernandez-Rivas M, Cardona V, et al. First European data from the network of severe allergic reaction (NORA). Allergy. 2014;69:1397-404.

2. Bilò MB. Anaphylaxis caused by Hymenoptera stings: from epidemiology to treatment. Allergy. 2011;66(Suppl 95):35-7.

3. Bonadonna P, Scaffidi L. Hymenoptera anaphylaxis as a clonal mast cell disorder. Immunol Allergy Clin N Am. 2018;38:455-68.

4. Bilò MB, Rueff F, Mosbech H, Bonifazi F, Oude-Elberink JNG. Diagnosis of Hymenoptera venom allergy. Allergy. 2005;60:1339-49. 
5. Bilò MB, Ollert M, Blank S. The role of component-resolved diagnosis in Hymenoptera venom allergy. Curr Opin Allergy Clin Immunol. 2019;19:614-22.

6. Muraro A, Roberts G, Bilò MB, Brockow K, Fernàndez Rivas M, Santos AF, et al. Anaphylaxis: guidelines from the European Academy of Allergy and Clinical Immunology. Allergy. 2014;69:1026-45.

7. Bilò MB, Cichocka-Jarosz E, Oude-Elberink JN, Lange J, Jakob T, Bonadonna P, et al. Self-medication of anaphylactic reactions due to Hymenoptera stings - an EAACI Task Force Consensus Statement. Allergy. 2016;71:931-43.

8. Sturm GJ, Varga EM, Roberts G, Mosbech H, Bilò MB, Adkis CA, et al. EAACl guidelines on allergen immunotherapy: Hymenoptera venom allergy. Allergy. 2018;73:744-64.

9. Vanhaecht K, De Witte K, Sermeus W. The impact of clinical pathways on the organisation of care processes ACCO 2007;1-18.

10. Lodewijckx C, Decramer M, Sermeus W, Panella M, Deneckere S, Vanhaecht K. Eight-step method to build the clinical content of an evidencebased care pathway: the case for COPD exacerbation. Trials. 2012;13:229.

11. Lawal AK, Rotter T, Kinsman L, Machotta A, Ronellenfitsch U, Scott S, et al. What is a clinical pathway? Refinement of an operational definition to identify clinical pathway studies for a Cochrane systematic review. BMC Med. 2016;14:35.

12. Flores EJ, Mull NK, Lavenberg JG, Mitchell MD, Leas BF, Williams A, et al. Using a 10-step framework to support the implementation of an evidence-based clinical pathways programme. BMJ Qual Saf. 2019;28(6):476-85.

13. Lodewijckx C, Sermeus W, Panella M, Deneckere S, Leigheb F, Troosters T, et al. Quality indicators for in-hospital management of exacerbation of chronic obstructive pulmonary disease: results of an international Delphi study. J Adv Nurs. 2013;69:348-62.

14. Donabedian A. Evaluating the quality of medical care. Reprinted from The Milbank memorial fund quarterly, 1966; 44:166-203. Milbank Q. 2005; 83(4):691-729. https://doi.org/10.1111/j.1468-0009.2005.00397.x.

15. Lavelle J, Schast A, Keren R. Standardizing care processes and improving quality using pathways and continuous quality improvement. Curr Treat Options Pediatr. 2015;1:347-58.

16. Campbell RL, Li JTC, Richard A. Emergency department diagnosis and treatment of anaphylaxis: a practice parameter. Ann Allergy Asthma Immunol. 2014;113:599-608.

17. Golden DBK, Demain J, Freeman T, Graft D, Tankersley M, Tracy J, et al. Stinging insect hypersensitivity A practice parameter update 2016. Ann Allergy Asthma Immunol. 2017;118:28-54.

18. Simons FER, Ardusso LRF, Bilò MB, El-Gamal YM, Ledford DK, Ring J, et al. World Allergy Organization anaphylaxis guidelines: summary. J Allergy Clin Immunol. 2011;127:587-93.
19. Anaphylaxis: assessment and referral after emergency treatment NICE 2018. Clinical guideline. Published: 14 December 2011.

20. Lieberman P, Nicklas RA, Randolph C, Oppenheimer J, Bernstein D, Bernstein J, et al. Anaphylaxis: a practice parameter update 2015. Ann Allergy Asthma Immunol. 2015;115:341-84.

21. Bonadonna P, Zanotti R, Pagani M, Bonifacio M, Scaffidi L, Olivieri E, et al. Anaphylactic reactions after discontinuation of Hymenoptera venom immunotherapy: a clonal mast cell disorder should be suspected. J Allergy Clin Immunol. 2017. https://doi.org/10.1016/j.jaip.2017.11.025.

22. Bonadonna P, Bonifacio M, Lombardo C, Zanotti R. Hymenoptera allergy and mast cell activation syndromes. Curr Allergy Asthma Rep. 2016;16:5.

23. Bonadonna P, Perbellini O, Passalacqua G, Caruso B, Colarossi S, Dal Fior $D$, et al. Clonal mast cell disorders in patients with systemic reactions to Hymenoptera stings and increased serum tryptase levels. J Allergy Clin Immunol. 2009;123:680-6.

24. Zanotti R, Lombardo C, Passalacqua G, Caimmi C, Bonifacio M, De Matteis $\mathrm{G}$, et al. Clonal mast cell disorders in patients with severe Hymenoptera venom allergy and normal serum tryptase levels. J Allergy Clin Immunol. 2015;136:135-9.

25. Greenhawt M, Akin C. Mastocytosis and allergy. Curr Opin Allergy Clin Immunol. 2007;7:387-92.

26. Broesby-Olsen S, Dybedal I, Gülen T, Kristensen TK, Moller MB, Akermann $L$, et al. Multidisciplinary management of mastocytosis: nordic expert group consensus. Acta Derm Venereol. 2016;96:602-12.

27. Valent P, Escribano L, Broesby-Olsen S, Hartmann K, Grattan C, Brockow K, et al. Proposed diagnostic algorithm for patients with suspected mastocytosis: a proposal of the European Competence Network on Mastocytosis. Allergy. 2014;69:1267-74.

28. Bilò MB, Pravettoni V, Bignardi D, Bonadonna P, Mauro M, Novembre E, et al. Hymenoptera venom allergy: management of children and adults in clinical practice. J Investig Allergol Clin Immunol. 2019. https://doi. org/10.18176/jiaci.0310

29. Panella M, Marchisio S, Di Stanislao F. Reducing clinical variations with clinical pathways: do pathways work? Reducing clinical variations with clinical pathways: do pathways work? Int J Qual Health Care. 2003;15:509-21.

\section{Publisher's Note}

Springer Nature remains neutral with regard to jurisdictional claims in published maps and institutional affiliations.
Ready to submit your research? Choose BMC and benefit from:

- fast, convenient online submission

- thorough peer review by experienced researchers in your field

- rapid publication on acceptance

- support for research data, including large and complex data types

- gold Open Access which fosters wider collaboration and increased citations

- maximum visibility for your research: over 100M website views per year

At BMC, research is always in progress.

Learn more biomedcentral.com/submissions 